\title{
Eigenvalues Analysis Applied to the Stability Study of a Variable Speed Pump Turbine Unit
}

\author{
M. Han, B. Kawkabani, J.-J. Simond
}

\begin{abstract}
This paper presents an eigenvalues analysis method for an induction machine model based on phase variables a,b,c. This approach is validated by comparison with a d,q approach and applied to a variable speed pump-turbine unit using a simplified model of the converters. The proposed approach permits the study and analysis of the interaction between mechanical, electric and regulation parts of the system.
\end{abstract}

Index Terms - control systems, numerical simulation, induction motors, AC-DC power converters, pumps, turbines, eigenvalues, transient analysis, variable speed drives.

\section{NOMENClAtURE}

$u \quad$ Voltage in $\mathrm{V}$

$R_{s,} R_{r} \quad$ Resistance of stator and rotor windings in $\Omega$

$i \quad$ Current in A

$L_{s}, L_{r} \quad$ Inductance of stator and rotor windings in $\mathrm{H}$

$L_{s r} \quad$ Mutual inductance between the stator and the rotor windings in $\mathrm{H}$

$\theta_{s}, \theta_{r} \quad$ Angle between the direct- axis and the axis of phase a of the stator respectively A of the rotor in $\mathrm{rad}$

$\theta_{m} \quad$ Angle between the axis of phase a of the stator and the axis of phase A of the rotor in rad

$\omega_{s}, \omega_{r}$ Angular speed of the rotating field of the stator respectively of the rotor in $\mathrm{rad} / \mathrm{s}$

$\omega_{m} \quad$ Angular speed of the rotor in $\mathrm{rad} / \mathrm{s}$

$S_{N} \quad$ Rated apparent power in VA

$P, Q \quad$ Active and reactive powers in $\mathrm{W}$ and Var

$P_{\text {mec }} \quad$ Mechanical power in $\mathrm{W}$

$U_{N} \quad$ Rated voltage in $\mathrm{V}$

$f_{N} \quad$ Rated frequency in $\mathrm{Hz}$

$J_{l}, J_{2} \quad$ Inertia of the rotor and of the turbine in $\mathrm{kgm}^{2}$

$K_{12} \quad$ Stiffness coefficient between the two inertias in $\mathrm{Nm} / \mathrm{rad}$

$D_{1}, D_{2}$ Viscous friction of the rotor, viscous friction of the turbine in $\mathrm{Nms} / \mathrm{rad}$

$T_{e m}, T_{\text {ext }}$ Electromagnetic and external torques in $\mathrm{Nm}$

$2 p \quad$ Number of poles

$T_{\text {reg }} \quad$ Time constant of the regulator in [s]

$T_{m e s} \quad$ Transient time constant of the lag in [s]

M. Han, B. Kawkabani and J.-J. Simond are with the EPFL, Ecole Polytechnique Fédérale de Lausanne at the Electrical Machinery Laboratory, CH-1015 Lausanne, Switzerland (phone: +41 2169326 80, fax: +41 $2169326 \quad 87$, e-mail: michel.han@epfl.ch, basile.kawkabani@epfl.ch, jean-jacques.simond@epfl.ch).

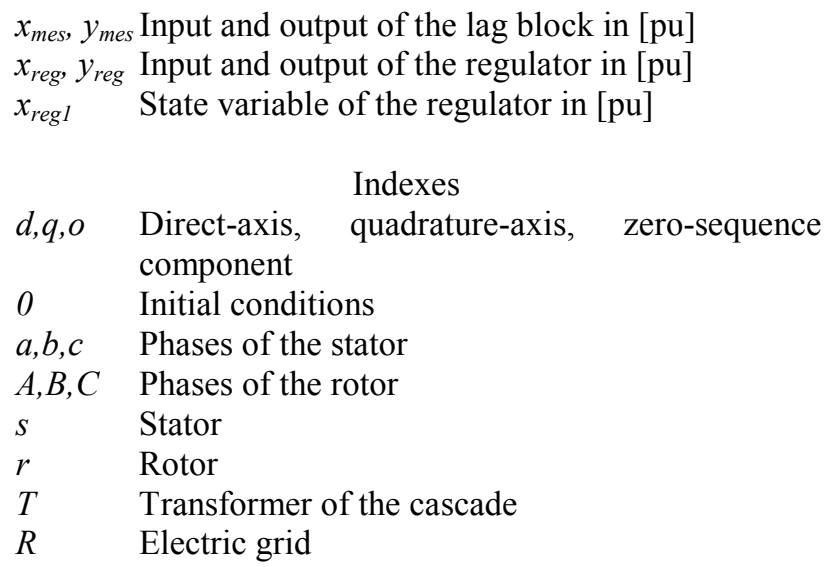

\section{INTRODUCTION}

$\mathrm{D}$ ue to the high volatility of wind power, electrical power networks particularly islanded ones, with high level of wind power penetration, may be subject to instabilities. Variable speed pump-turbine units can significantly increase the stability of electrical power networks, and thus overcome this problem [1]-[5].

The study, modeling and analysis of the dynamic behavior of variable speed pump-turbine units have been presented and published in several papers in the last decade [6]-[15]. The aim of this study is to develop an analytical approach based on the eigenvalues analysis method in order to facilitate the study of the interactions between the hydraulic, electric and regulation parts of a variable speed pump-turbine unit, and to identify the origin of eventual instabilities.

A similar method has been applied efficiently to a complete hydroelectric production site with a synchronous generator by using $a, b, c$ phase variables instead of $d-q$ components [16].

The advantage of the extension of the eigenvalue analysis method to a, b, c phase variables instead of d-q components is mainly the possibility of the application of this method to any symmetrical or asymmetrical mode of operation of the machine without specific additional developments. Moreover, most of developed software packages dedicated to the numerical simulation of power systems [17] use phase variables as state variables, because of the simplicity of linking together different elements. The implementation of the eigenvalue analysis method in such software packages constitutes a real advantage for the analysis of complex topologies. 
The paper is organized as follows: Section III presents the application of the eigenvalues method on a simple topology of an induction machine before introducing the variable speed unit with a simplified model of the converters. The simulation results and validation of the approach are presented and discussed in Section IV, for two studied cases. Finally, conclusions are given in Section $\mathrm{V}$.

\section{Modeling OF THE VARIABLE SPEED UNIT}

\section{A. Eigenvalues Analysis Method based on phase variables applied on an induction machine}

The simple topology to validate the linearized model of an induction machine is composed of a doubly-fed induction machine connected to an infinite grid. Two mechanical masses representing the rotor and the pumpturbine are considered, as illustrated in Fig.1.

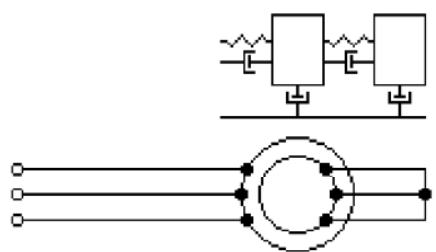

Fig. 1 Simple topology of an induction machine

The terminal voltages of the machine in the phase coordinate system are expressed as:

$u_{a}=u_{d s} \cos \theta_{s}-u_{q s} \sin \theta_{s}+u_{o s}$

$u_{b}=u_{d s} \cos \left(\theta_{s}-\frac{2 \pi}{3}\right)-u_{q s} \sin \left(\theta_{s}-\frac{2 \pi}{3}\right)+u_{o s}$

$u_{c}=u_{d s} \cos \left(\theta_{s}+\frac{2 \pi}{3}\right)-u_{q s} \sin \left(\theta_{s}+\frac{2 \pi}{3}\right)+u_{o s}$

$u_{A}=u_{d r} \cos \theta_{r}-u_{q r} \sin \theta_{r}+u_{o r}$

$u_{B}=u_{d r} \cos \left(\theta_{r}-\frac{2 \pi}{3}\right)-u_{q r} \sin \left(\theta_{r}-\frac{2 \pi}{3}\right)+u_{o r}$

$u_{C}=u_{d r} \cos \left(\theta_{r}+\frac{2 \pi}{3}\right)-u_{q r} \sin \left(\theta_{r}+\frac{2 \pi}{3}\right)+u_{o r}$

The small oscillating components of all the stator and rotor quantities are analyzed by the linearization of the set of equations around an operating point, defined by $\mathrm{P}_{\text {mec } 0}$, $\omega_{0}, U_{n 0}$. These ones are due to the oscillations of the rotor. The modeling of the oscillating coordinates is represented in Fig 2.

Hence, the oscillating components of the terminal voltage on the stator and rotor side, respectively ' $\mathrm{a}$ ' and ' $\mathrm{A}$ ' are given by:

$\Delta u_{a}=\Delta u_{d s} \cos \theta_{s}-\Delta u_{q s} \sin \theta_{s}+\Delta u_{o s}$

$\Delta u_{A}=\Delta u_{d r} \cos \theta_{r}-\Delta u_{q r} \sin \theta_{r}+\Delta u_{o r}$

Both complete expressions are established by replacing the expressions of $\Delta \mathrm{u}_{\mathrm{ds}}, \Delta \mathrm{u}_{\mathrm{q}}, \Delta \mathrm{u}_{\mathrm{os}}$ and $\Delta \mathrm{u}_{\mathrm{dr}}, \Delta \mathrm{u}_{\mathrm{qr}}, \Delta \mathrm{u}_{\mathrm{or}}$ given in Appendix in $\mathrm{Eq}$ (7) and $\mathrm{Eq}$ (8). The set of equations is completed by the swing equations of the two mechanical masses, given by:

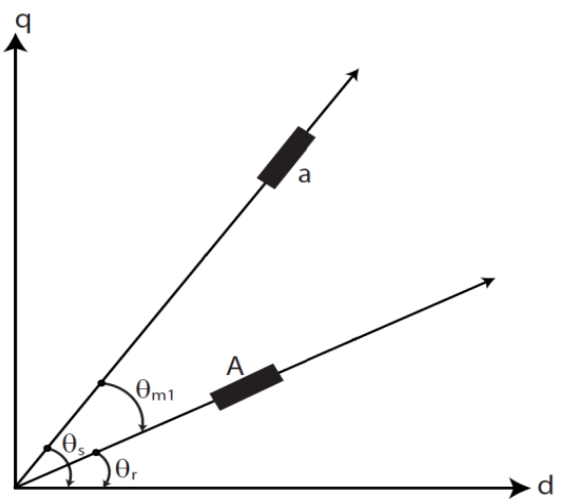

Fig. 2 Rotating coordinates of the induction machine

$\frac{J_{1}}{p} \frac{d \omega_{m 1}}{d t}=T_{e m}-D_{1} \omega_{m 1}-\frac{k_{12}}{p}\left(\theta_{m 1}-\theta_{m 2}\right)$

$\frac{J_{2}}{p} \frac{d \omega_{m 2}}{d t}=\frac{k_{12}}{p}\left(\theta_{m 1}-\theta_{m 2}\right)-D_{2} \omega_{m 2}+T_{e x t}$

The complete topology of a variable speed pump-turbine unit electrical system is illustrated in Fig.3. This model includes the doubly-fed induction motor-generator with a two-level Voltage Source Inverters (VSI) cascade in the rotor side. In order to enable the linearization of the converter and the control system, an equivalent pseudo continuous model is used for the converters (Fig.4). The VSI is therefore replaced by an equivalent voltage source driven by the control system.

The electrical system can be divided into two sections, a transformer section and a machine one. The transformer section operates as a Static Var Compensator (SVC), its main role being to exchange reactive power with the grid. The reactive power and the capacitors voltage can be controlled by acting on the transformer primary side currents through the left-side converter.

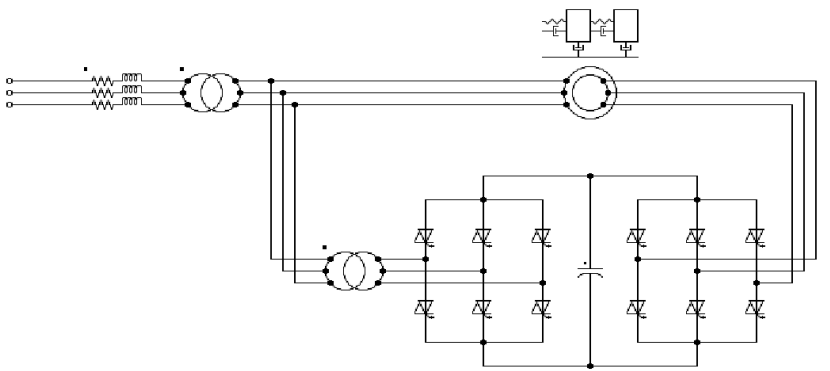

Fig. 3 Layout of a 2-level variable speed unit

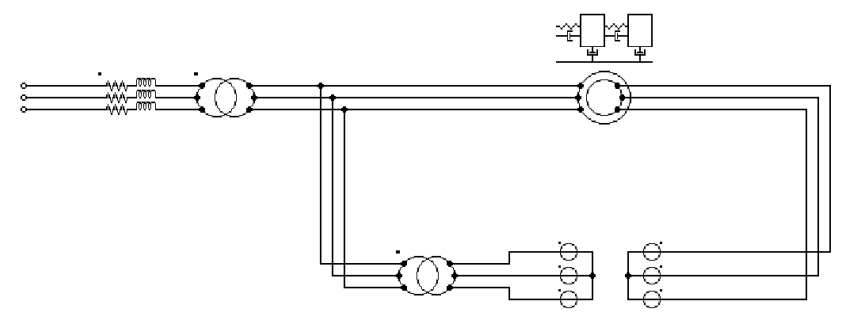

Fig. 4 Simplified model of the variable speed unit 
B. Eigenvalues Analysis Method based on phase variables applied on a variable speed unit with a simplified model of the converters

The linearization of the variable speed unit does not modify the equations which describe the behavior of an induction machine, therefore the equations (1) to (10) remain unchanged. By considering the transmission line and the intermediate transformer between the electrical network and the system, some modifications of the set of linearized equations are necessary as follows:

$$
\begin{aligned}
\Delta u_{a R}= & \Delta u_{d R}^{\prime \prime} \cos \theta_{s}-\Delta u_{q R}^{\prime \prime} \sin \theta_{s}+\Delta u_{o R}^{\prime \prime} \\
\Delta u_{b R}= & \Delta u_{d R}^{\prime \prime} \cos \left(\theta_{s}-\frac{2 \pi}{3}\right)-\Delta u_{q R}^{\prime \prime} \sin \left(\theta_{s}-\frac{2 \pi}{3}\right) \\
& +\Delta u_{o R}^{\prime \prime} \\
\Delta u_{c R} & =\Delta u_{d R}^{\prime \prime} \cos \left(\theta_{s}+\frac{2 \pi}{3}\right)-\Delta u_{q R}^{\prime \prime} \sin \left(\theta_{s}+\frac{2 \pi}{3}\right) \\
& +\Delta u_{o R}^{\prime \prime}
\end{aligned}
$$

The transformers are modeled with their short-circuit impedances, hence the expressions become:

$$
\begin{aligned}
\Delta u_{a T}= & \Delta u_{d T}^{\prime \prime} \cos \theta_{s}-\Delta u_{q T}^{\prime \prime} \sin \theta_{s}+\Delta u_{o T}^{\prime \prime} \\
\Delta u_{b T} & =\Delta u_{d T}^{\prime \prime} \cos \left(\theta_{s}-\frac{2 \pi}{3}\right)-\Delta u_{q T}^{\prime \prime} \sin \left(\theta_{s}-\frac{2 \pi}{3}\right) \\
& +\Delta u_{o T}^{\prime \prime} \\
\Delta u_{c T} & =\Delta u_{d T}^{\prime \prime} \cos \left(\theta_{s}+\frac{2 \pi}{3}\right)-\Delta u_{q T}^{\prime \prime} \sin \left(\theta_{s}+\frac{2 \pi}{3}\right) \\
& +\Delta u_{o T}^{\prime \prime}
\end{aligned}
$$

The complete expressions of these terminal voltages are obtained by combining the equations (11) to (13) with the expressions of the transformers and the equations from the machine.

The transformer and machine control systems are represented respectively in Fig. 5 and Fig. 6.

In both control systems, there are only two types of functions blocks. The first one is LAG-function modeling the lag caused by the measurements of each quantity. The related linearized equation is given by:

$$
T_{\text {mes }} \frac{d}{d t} \Delta y_{\text {mes }}=k \cdot \Delta x_{\text {mes }}-\Delta y_{\text {mes }}
$$

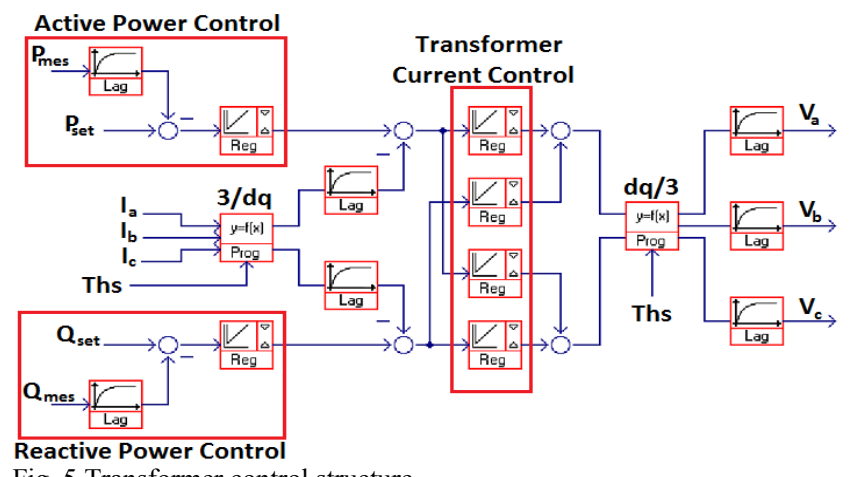

Fig. 5 Transformer control structure

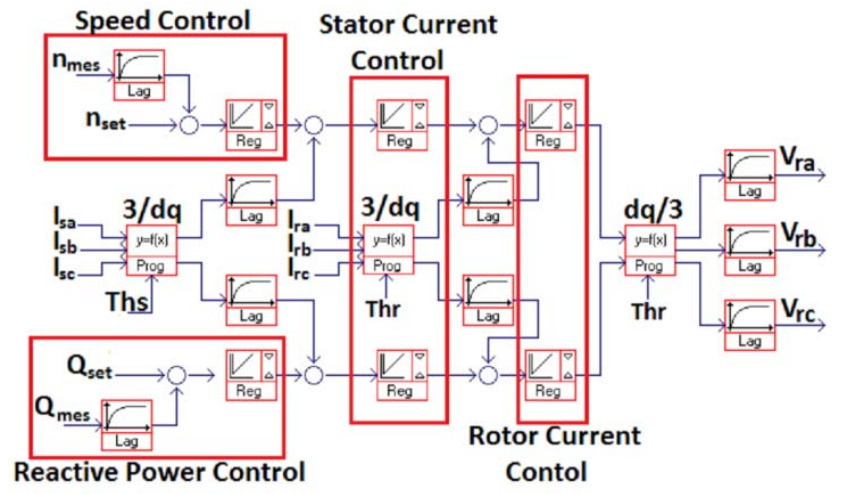

Fig. 6 Machine control structure

The second type is related to the regulator PI and its linearized set of equations is expressed as follows:

$$
\left\{\begin{array}{c}
T_{r e g} \frac{d}{d t} \Delta x_{r e g 1}=\Delta y_{r e g}-\Delta x_{r e g 1} \\
\Delta y_{r e g}=k \cdot \Delta x_{r e g}+\Delta x_{r e g 1}
\end{array}\right.
$$

The fact that the outputs of the control systems are written in function of the state variables ensures that the whole system is in closed loop and thus stable.

\section{Simulation Results AND VAlidation OF THE APPROACH}

\section{Induction Machine Model}

The validation of the proposed approach has been performed with a simple topology (Fig.1). The parameters of the induction machine as well as both mechanical masses are reported in Table I.

TABLE I

Rated Values Of The Power-Plant

\begin{tabular}{ll}
\hline Induction machine & Mechanical masses \\
$\mathrm{S}_{\mathrm{N}}=380[\mathrm{MVA}]$ & $\mathrm{J}_{1}=2.661 \cdot 10^{6}\left[\mathrm{kgm}^{2}\right]$ \\
$\mathrm{U}_{\mathrm{NS}}=18[\mathrm{kV}]$ & $\mathrm{J}_{2}=133.05 \cdot 10^{3}\left[\mathrm{kgm}^{2}\right]$ \\
$\mathrm{F}_{\mathrm{N}}=60[\mathrm{~Hz}]$ & $\mathrm{D}_{1}=5000[\mathrm{Nms} / \mathrm{rad}]$ \\
$\mathrm{p}=8[-]$ & $\mathrm{D}_{2}=5000[\mathrm{Nms} / \mathrm{rad}]$ \\
$\mathrm{r}_{\mathrm{s}}=0.00174401[\mathrm{pu}]$ & $\mathrm{k}_{12}=5 \cdot 10^{11}[\mathrm{Nm} / \mathrm{rad}]$ \\
$\mathrm{x}_{\sigma \mathrm{s}}=0.26037[\mathrm{pu}]$ & \\
$\mathrm{x}_{\mathrm{hs}}=4.19759[\mathrm{pu}]$ & \\
$\mathrm{x}_{\mathrm{\sigma r}}=0.272099[\mathrm{pu}]$ & \\
$\mathrm{r}_{\mathrm{r}}{ }^{\prime}=0.00201494[\mathrm{pu}]$ & \\
\hline
\end{tabular}

The calculated eigenvalues resulting from the d,q,o and a,b,c approaches related to the studied system are reported in Table II in the form $\lambda_{i}=\alpha_{i}+j \omega_{i}$. Since both approaches are equivalent, the obtained values are the same.

TABLE II

EIGENVALUES AsSOCIATED TO D,Q,O AND A,B,C APPROACHES

\begin{tabular}{cc}
\hline & {$\left[\lambda_{\mathrm{dqo}}\right]=\left[\lambda_{\mathrm{abc}}\right]$} \\
Torsional mode 0 & $-0.83 \pm 5.948$ \\
Torsional mode 1 & $-0.143 \pm 1986.426$ \\
& $-1.275 \pm 376.987$ \\
Electrical network & -1.306 \\
& -2.525 \\
& -2.791 \\
\hline
\end{tabular}


One can identify the torsional mode $0(\mathrm{f}=0.947[\mathrm{~Hz}])$ or mode 1 related to a mechanical system with two inertias, as well as the frequency of the electrical network. In addition, some time constants can be defined analytically as follows:

$$
\begin{aligned}
& \frac{1}{T_{1}}=\frac{R_{s}}{L_{o s}}=2.525[\mathrm{~s}] \\
& \frac{1}{T_{2}}=\frac{R_{r}}{L_{o r}}=2.791[\mathrm{~s}]
\end{aligned}
$$

The identification of the torsional mode 0 is obtained by a numerical simulation allowing at the same time to validate the torsional mode 1 . The machine is initially operating at $\mathrm{P}_{\text {méc }}=0.5[\mathrm{pu}]$ while the external torque is reduced from $0.5[\mathrm{pu}]$ to $0[\mathrm{pu}]$ at $\mathrm{t}=0.5[\mathrm{~s}]$. The rotational speed is then left to evolve freely to its equilibrium point, as illustrated in Fig. 7. The analysis of the results is summarized in Table III.

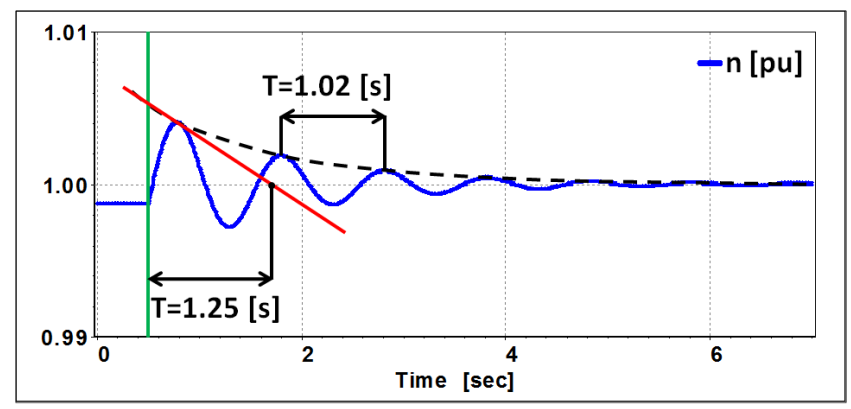

Fig. 7 Speed of the rotor

One can notice the good agreement between the results obtained by the two approaches.

TABLE III

COMPARison of The Results Related To Mode 0

\begin{tabular}{ccc}
\hline & Eigenvalues & Numerical \\
$-1 / \alpha[\mathrm{s}]$ & 1.21 & 1.25 \\
$\omega[\mathrm{rad} / \mathrm{s}]$ & 5.948 & 6.16 \\
\hline
\end{tabular}

In addition, the pulsation of the mode 1 is identified when the oscillations period of the transmitted torque is measured on the same simulation.

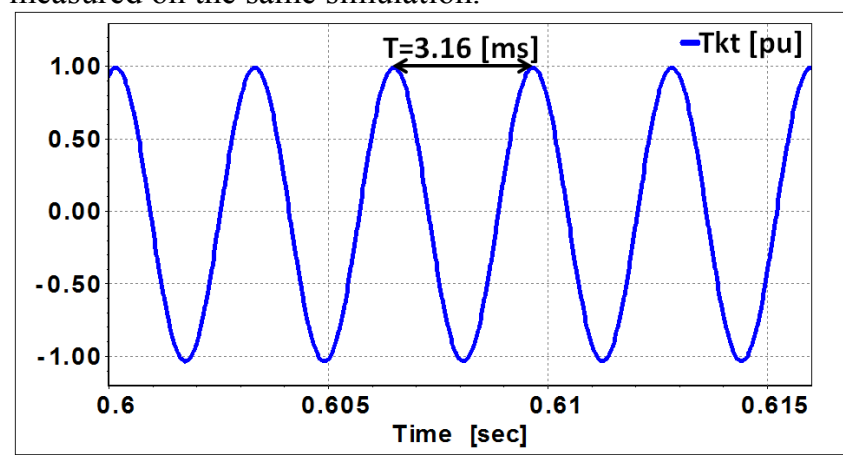

Fig. 8 Transmitted torque between the two inertias

A good agreement between the analytical value and estimated one from the simulation is obtained as shown in Table IV.
TABLE IV

COMPARISON OF THE RESUlTS FOR MODE 1

\begin{tabular}{ccc}
\hline & Eigenvalues & Numerical \\
$\omega[\mathrm{rad} / \mathrm{s}]$ & 1986.426 & 1987 \\
\hline
\end{tabular}

Therefore, one can notice that the results obtained by the eigenvalues analysis method applied to the induction machine are in good agreement with the ones obtained by the numerical simulations, which validates in this case the proposed approach.

\section{Variable Speed Unit}

The parameters of the variable speed unit, designed for a maximum slip of $7 \%$, are summarized in Table V. The induction machine of the unit is reported in Table I.

TABLE V

RATED VALUES OF THE TRANSFORMERS AND PARAMETERS OF THE TRANSMISSION LINE

\begin{tabular}{ll}
\hline $\begin{array}{l}\text { Transformer of the } \\
\text { electrical network }\end{array}$ & $\begin{array}{l}\text { Transformer of the } \\
\text { cascade }\end{array}$ \\
$\mathrm{S}_{\mathrm{NT}}=380[\mathrm{MVA}]$ & $\mathrm{S}_{\mathrm{NT}}=26.67[\mathrm{MVA}]$ \\
$\mathrm{U}_{\mathrm{NT} 1}=500[\mathrm{kV}]$ & $\mathrm{U}_{\mathrm{NT} 1}=18[\mathrm{kV}]$ \\
$\mathrm{U}_{\mathrm{NT2}}=18[\mathrm{kV}]$ & $\mathrm{U}_{\mathrm{NT2}}=2[\mathrm{kV}]$ \\
$\mathrm{r}_{\mathrm{cc}}=0.003[\mathrm{pu}]$ & $\mathrm{r}_{\mathrm{cc}}=0.005[\mathrm{pu}]$ \\
$\mathrm{X}_{\mathrm{cc}}=0.14[\mathrm{pu}]$ & $\mathrm{x}_{\mathrm{cc}}=0.15[\mathrm{pu}]$ \\
Coupling : Yy & Coupling : Yy \\
\hline Transmission Line & \\
$\mathrm{R}_{\mathrm{L}}=0.01[\Omega]$ & \\
$\mathrm{L}_{\mathrm{L}}=0.001[\Omega]$ & \\
\hline
\end{tabular}

The chosen operating point for the variable speed unit is at $\mathrm{P}_{\text {stator0 }}=-0.5[\mathrm{pu}], \mathrm{Q}_{\text {stator0 }}=0[\mathrm{pu}]$ and $\mathrm{s}_{0}=-1 \%$. By applying the developed eigenvalues analysis method on the complete system shown in Fig. 4, 41 eigenvalues have been determined. The complete list of the eigenvalues is given in Tables VI and VII, related to the electrical and mechanical systems respectively to the control system.

TABLE VI

List Of EIgenvalues Related to The Electrical And Mechanical SYSTEMS

\begin{tabular}{cc}
\hline $\mathrm{i}$ & Eigenvalues $\lambda_{\mathrm{i}}$ \\
$1-2$ & $-0.144 \pm \mathrm{j} 1986.425$ \\
$3-4$ & $-33.994 \pm \mathrm{j} 378.968$ \\
$5-6$ & $-2.74 \pm \mathrm{j} 376.798$ \\
$7-8$ & $-26.48 \pm \mathrm{j} 3.634$ \\
9 & -2.791 \\
10 & -12.566 \\
11 & -4.475 \\
12 & $-9.115 \cdot 10^{-9}$ \\
13 & $-4.642 \cdot 10^{-3}$ \\
\hline
\end{tabular}

One can recognize several imaginary parts of the eigenvalues similar to the case with the only induction machine such as the torsional mode $1\left(\lambda_{1,2}\right)$, the pulsation of the electrical network $\left(\lambda_{5,6}\right)$ or the one related to the time constant $\left(\lambda_{9}\right)$. One can notice that an additional pair of 
eigenvalues $\left(\lambda_{3,4}\right)$ is present. These eigenvalues might be from the cascade since their imaginary parts are close to the electrical grid pulsation. Nevertheless, this point will be confirmed by an investigation on the cascade transformer during a simulation illustrated in Fig. 9.

The machine is initially operating at the mentioned operating point at $\mathrm{P}_{\text {stator } 0}=-0.5[\mathrm{pu}], \mathrm{Q}_{\text {stator } 0}=0[\mathrm{pu}]$ and $\mathrm{s}_{0}=-$ $1 \%$, then the external torque is reduced to $0[\mathrm{pu}]$.

TABLE VII

COMPlete List Of Eigenvalues Related To The Control System

\begin{tabular}{|c|c|}
\hline $\mathrm{i}$ & Eigenvalues $\lambda_{\mathrm{i}}$ \\
\hline 14 & -570 \\
\hline 15 & -570 \\
\hline 16 & -570 \\
\hline 17 & -570 \\
\hline 18 & -570 \\
\hline 19 & -570 \\
\hline $20-21$ & $-3394.73 \pm \mathrm{j} 0.024$ \\
\hline 22 & -3420 \\
\hline 23 & -80.643 \\
\hline 24 & -80.643 \\
\hline 25 & -2.937 \\
\hline 26 & -2.937 \\
\hline 27 & -16.48 \\
\hline 28 & -15.186 \\
\hline 29 & -1080 \\
\hline 30 & -1080 \\
\hline 31 & -1080 \\
\hline 32 & -1080 \\
\hline 33 & -6458.0963 \\
\hline 34 & -6458.8655 \\
\hline 35 & -6480 \\
\hline 36 & -8.078 \\
\hline 37 & -8.078 \\
\hline 38 & -0.707 \\
\hline 39 & -0.707 \\
\hline 40 & -162 \\
\hline 41 & -10 \\
\hline
\end{tabular}

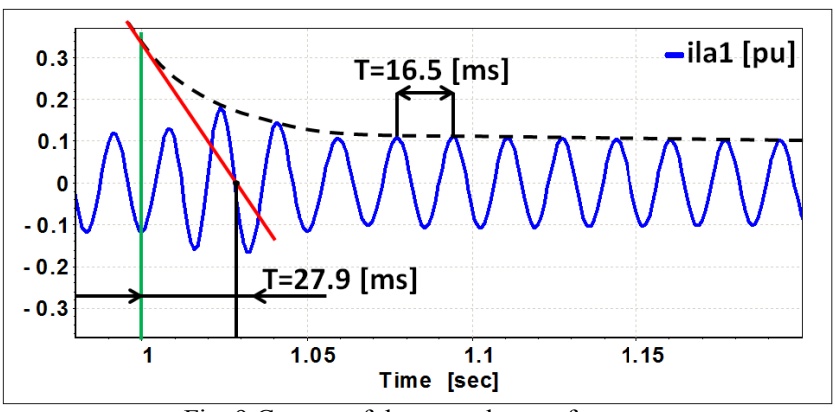

Fig. 9 Current of the cascade transformer

The pulsation of the transformer current in the cascade is equal to $380.8[\mathrm{rad} / \mathrm{s}]$ with a damping time constant of $0.0279[\mathrm{~s}]$. These values are in good agreement with the values obtained by the eigenvalues approach as shown in Table VIII.
TABLE VIII

COMPARISON OF RESULTS COMING FROM BOTH APPROACHES

\begin{tabular}{ccc}
\hline & Eigenvalues & Numerical \\
$-1 / \alpha[\mathrm{s}]$ & 0.0294 & 0.0279 \\
$\omega[\mathrm{rad} / \mathrm{s}]$ & 378.968 & 380.8 \\
\hline
\end{tabular}

From the operating point $\mathrm{P}_{\text {stator }}=-0.5[\mathrm{pu}], \mathrm{Q}_{\text {stator } 0}=0[\mathrm{pu}]$ but with a slip $\mathrm{s}_{1}=-1 \%$ or $\mathrm{s}_{2}=-7 \%$, the pair of eigenvalues $\left(\lambda_{7,8)}\right.$ can be identified, as related to the electrical components of the rotor. The simulation and the analytical results are reported in Table IX. One can notice that the obtained eigenvalues depend on the operating point of the machine.

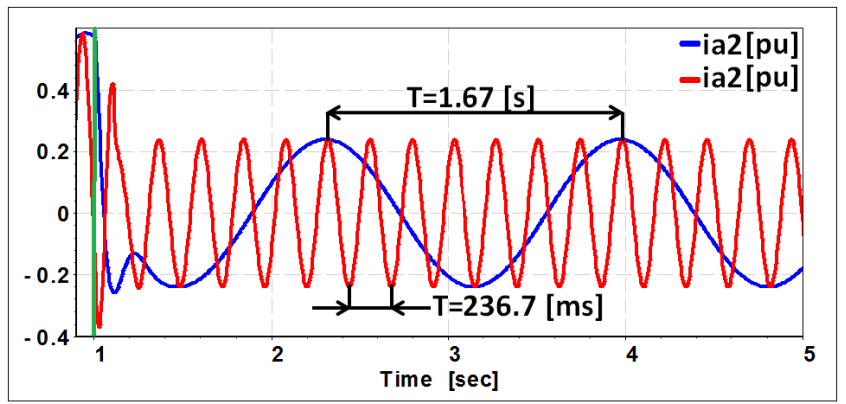

Fig. 10 Current of the rotor with a slip of $1 \%$ (blue) and $7 \%$ (red)

TABLE IX

COMPARISON Of Results Related To THE CuRRent Of THE Rotor

\begin{tabular}{lcc}
\hline & Eigenvalues & Numerical \\
$\omega[\mathrm{rad} / \mathrm{s}]\left(\mathrm{s}_{1}=-1 \%\right)$ & 3.634 & 3.762 \\
$\omega[\mathrm{rad} / \mathrm{s}]\left(\mathrm{s}_{2}=-7 \%\right)$ & 26.427 & 26.544 \\
\hline
\end{tabular}

Finally, some time constants have been slightly modified by adding the intermediate transformer and the transmission lines between the grid and the variable speed unit. This results in a modification of the time constant values given by $\lambda_{10}$ and $\lambda_{11}$, as

$$
\begin{gathered}
\frac{1}{T_{3}}=\frac{R_{c c T}}{L_{c c T}}=12.566[\mathrm{~s}] \\
\frac{1}{T_{1}^{\prime}}=\frac{R_{s}+R_{c c R}+R_{L}}{L_{o s}+L_{c c R}+L_{L}}=4.475[\mathrm{~s}]
\end{gathered}
$$

In Table VII, all the eigenvalues are related to different blocks of the control systems shown in Fig.5 and Fig.6. All these eigenvalues represent the time constants of the regulators or the LAG functions which can be easily determined.

\section{CONCLUSIONS}

This paper presents a detailed approach of the eigenvalues analysis method based on phase variables applied to a variable speed pump-turbine unit. This approach applied first to a simple topology with an induction machine has been validated by comparing the results with the ones obtained by the classical d,q,o approach. The proposed a,b,c approach has been then applied successfully to a complete variable speed pumpturbine unit using a simplified model of the converters. The 
implementation of this analytical approach model in a modular software package permits a fast and efficient analysis of the interaction between the mechanical, electrical and control systems of a variable speed pumpturbine unit.

\section{REFERENCES}

[1] H. K. Happoldt, O. J. Hartmann, E. Wiedemann, "The present state of pumped storage in Europe," IEEE Transactions on Power Apparatus and Systems, vol. 82, issue 68, pp. 618-631, October 1963.

[2] J.-J. Simond, A. Sapin, D. Schafer, "Expected benefits of adjustable speed pumped storage in the European network," Hydropower into the next century, pp. 579-585, Gmunden, Austria , 1999.

[3] K. Grotenburg, F. Koch, I. Erlich, U. Bachmann, "Modeling and dynamic simulation of variable speed pump storage unit incorporated into the German Electric Power System," EPE 2001, Graz, Austria, 2001.

[4] A. Schwery, E. Fass, J.-M. Henry, W. Bach, A. Mirzaian, "Pump storage power plants, ALSTOM's long experience and technological innovation," Hydro 2005, Villach, Austria, 2005.

[5] Y. Pannatier, B. Kawkabani, G. Sari, J.-J. Simond, "Stability Studies of a Mixed Islanded Power Network with Varspeed Units using Simplified Models of the Converters", IEEE ECCE 2010, Atlanta, Georgia, September 2010.

[6] O. H. Souza Jr., N. Barbieri, A.H.M. Santos, "Study of hydraulic transients in hydropower plants through simulation of nonlinear model of penstock and hydraulic turbine model", IEEE Transactions on Power Systems, vol. 14, issue 4, pp. 1269-1272, 1999.

[7] H. Fang, L. Chen, N. Dlakavu, Z. Shen, "Basic modeling and simulation tool for analysis of hydraulic transients in hydroelectric power plants", IEEE Transactions on Energy Conversion, vol. 23, issue 3, pp. 834-841, September 2008.

[8] E. Kopf, S. Brausewetter, M. Giese, and F. Moser, "Optimized control strategies for variable speed machines," in Proc. 22nd IAHR Symp. Hydraulic Mach. Syst., Stockholm, Sweden, Jun. 29 - Jul. 2, 2004, Paper A15-2, pp. 1-9..

[9] T. Kuwabara, A. Shibuya, H. Furuta, E. Kita, K. Mitsuhashi, "Design and dynamic response characteristics of $400 \mathrm{MW}$ adjustable speed pumped storage unit for Ohkawachi power station," IEEE Transactions on Energy Conversion, vol. 11, issue 2, pp. 376-384, June 1996.

[10] J.-K. Lung, Y. Lu, W.-L. Hung, W.-S. Kao, "Modeling and dynamic simulations of doubly fed adjustable-speed pumped storage units," IEEE Transactions on Energy Conversion, vol. 22, issue 2, pp. 250258, June 2007.

[11] A. Bocquel, J. Janning, "Analysis of a $300 \mathrm{MW}$ variable speed drive for pump-storage plant applications," European Conference on Power Electronics and Applications, pp. 1-10, 2005.

[12] J. Fraile-Ardanuy, J. R. Wilhelmi, J. J. Fraile-Mora, J. I. Pérez, "Variable-speed hydro generation: operational aspects and control," IEEE Transactions on Energy Conversion, vol. 21, issue 2, pp. 569574, June 2006.

[13] C. Nicolet, B. Greiveldinger, J.-J. Hérou, B. Kawkabani, Ph. Allenbach, J.-J. Simond, F. Avellan, "High-order modeling of hydraulic power plant in islanded power network," IEEE Transactions on Power Systems, vol. 22, issue 4, pp. 1870-1880, November 2007.

[14] E. Levi, "Multiphase electric machines for variable-speed applications," IEEE Transactions on Industrial Electronics, vol. 55, issue 5, pp. 1893-1909, May 2008.

[15] G. Iwanski, W. Koczara, "DFIG-based power generation system with UPS function for variable-speed applications," IEEE Transactions on Industrial Electronics, vol. 55, issue 8, pp. 30473054, August 2008.

[16] P. C. O Silva, B. Kawkabani, S. Alligné, C. Nicolet, J.-J. Simond, F. Avellan, "Stability Study of a Complete Hydroelectric Production Site by Eigenvalues Analysis Method Based on Phase Variables", ICEM 2010 - XIX International Conference on Electrical Machines, Rome, Italy, September 2010.

[17] Software package Simsen Home Page, http://simsen.epfl.ch.
Michel Han graduated from the EPFL and received his Master degree in Electrical Engineering in 2011. His main field of interest is the modeling and simulation of variable speed units in transient operation.

Basile Kawkabani (M'00-SM'11) received his master degree in 1978 from SUPELEC, Ecole Supérieure d'Electricité in Paris France, and his $\mathrm{PhD}$ degree in 1984 in Electrical Engineering from the Swiss Federal Institute of Technology in Lausanne (EPFL). From 1992 to 2010, he was lecturer and research associate at the EPFL Electrical Machinery Laboratory. He is currently a senior scientist in STI Scientists Group (Electrical Machinery - EPFL), and senior member of the IEEE. His interests include modeling of power systems, power system stability and control.

Jean-Jacques Simond (M'00) graduated in Electrical Engineering in 1967 and got his doctoral degree in 1976 from EPFL, the Swiss Federal Institute of Technology in Lausanne. Till 1990 he was working for BBC / ABB first as R\&D engineer and later as head of the technical department for Hydro- and Diesel-generators. He was director of the Electrical Machinery Laboratory of the EPFL till 2011. Professor Emeritus from EPFL, he is also consultant for international electrical machines manufacturers and utilities.

\section{APPENDIX}

d,q,o approach : Linearized equations of the induction machine given in real quantities in the stator reference frame.

$$
\begin{aligned}
\Delta u_{d s}= & R_{s} \Delta i_{d s}+L_{s} \frac{d}{d t} \Delta i_{d s}+L_{s r} \frac{d}{d t} \Delta i_{d r} \\
\Delta u_{q s}= & R_{s} \Delta i_{q s}+L_{s} \frac{d}{d t} \Delta i_{q s}+L_{s r} \frac{d}{d t} \Delta i_{q r} \\
\Delta u_{o s}= & R_{s} \Delta i_{o s}+L_{o s} \frac{d}{d t} \Delta i_{o s} \\
\Delta u_{d r}= & R_{r} \Delta i_{d r}+L_{r} \frac{d}{d t} \Delta i_{d r}+L_{s r} \frac{d}{d t} \Delta i_{d s} \\
& +\omega_{m 0} L_{r} \Delta i_{q r}+\omega_{m 0} L_{s r} \Delta i_{q s}+\Delta \omega_{m}\left(L_{r} i_{q r 0}+L_{s r} i_{q s 0}\right) \\
\Delta u_{q r}= & R_{r} \Delta i_{q r}+L_{r} \frac{d}{d t} \Delta i_{q r}+L_{s r} \frac{d}{d t} \Delta i_{q s} \\
& -\omega_{m 0} L_{r} \Delta i_{d r}-\omega_{m 0} L_{s r} \Delta i_{d s}+\Delta \omega_{m}\left(L_{r} i_{d r 0}+L_{s r} i_{d s 0}\right) \\
\Delta u_{o r}= & R_{r} \Delta i_{o r}+L_{o r} \frac{d}{d t} \Delta i_{o r}
\end{aligned}
$$

Set of equations related to the transformers given in real quantities:

$$
\begin{aligned}
& \Delta u_{d T}^{\prime}=R_{c c T}^{\prime} \Delta i_{d T}+L_{c c T}^{\prime} \frac{d}{d t} \Delta i_{d T}+\Delta u_{d v s i}^{\prime} \\
& \Delta u_{q T}^{\prime}=R_{c c T}^{\prime} \Delta i_{q T}+L_{c c T}^{\prime} \frac{d}{d t} \Delta i_{q T}+\Delta u_{q v s i}^{\prime} \\
& \Delta u_{o T}^{\prime}=R_{c c T}^{\prime} \Delta i_{o T}+L_{c c T}^{\prime} \frac{d}{d t} \Delta i_{o T}
\end{aligned}
$$

Set of equations related to the grid:

$$
\begin{aligned}
& \Delta u_{d R}^{\prime \prime}=\left(R_{c c R}^{\prime \prime}+R_{L}^{\prime \prime}\right) \Delta i_{d R}+\left(L_{c c R}^{\prime \prime}+L_{L}^{\prime \prime}\right) \frac{d}{d t} \Delta i_{d R}+\Delta u_{d s} \\
& \Delta u_{q R}^{\prime \prime}=\left(R_{c c R}^{\prime \prime}+R_{L}^{\prime \prime}\right) \Delta i_{q R}+\left(L_{c c R}^{\prime \prime}+L_{L}^{\prime \prime}\right) \frac{d}{d t} \Delta i_{q R}+\Delta u_{q s} \\
& \Delta u_{o R}^{\prime \prime}=\left(R_{c c R}^{\prime \prime}+R_{L}^{\prime \prime}\right) \Delta i_{o R}+\left(L_{c c R}^{\prime \prime}+L_{L}^{\prime \prime}\right) \frac{d}{d t} \Delta i_{o R}+\Delta u_{o s}
\end{aligned}
$$


a,b,c approach : Linearized equations of an induction machine given in real quantities in the stator reference frame.

$$
\begin{aligned}
& \Delta u_{a}=\frac{d}{d t} \Delta i_{a}\left(\frac{2}{3} L_{s}+\frac{1}{3} L_{o s}\right) \\
& +\frac{d}{d t} \Delta i_{b}\left(-\frac{1}{3} L_{s}+\frac{1}{3} L_{o s}\right) \\
& +\frac{d}{d t} \Delta i_{c}\left(-\frac{1}{3} L_{s}+\frac{1}{3} L_{o s}\right) \\
& +\frac{d}{d t} \Delta i_{A}\left(\frac{2}{3} L_{s r} \cos \left(\theta_{s}-\theta_{r}\right)\right) \\
& +\frac{d}{d t} \Delta i_{B}\left(\frac{2}{3} L_{s r} \cos \left(\theta_{s}-\theta_{r}-\frac{2 \pi}{3}\right)\right) \\
& +\frac{d}{d t} \Delta i_{C}\left(\frac{2}{3} L_{s r} \cos \left(\theta_{s}-\theta_{r}+\frac{2 \pi}{3}\right)\right) \\
& +\Delta i_{a}\left(R_{s}\right) \\
& \Delta T_{e m}=\frac{2}{3} p L_{s r}\left(\Delta i _ { A } \left(i_{a, 0} \sin \left(\theta_{r}-\theta_{s}\right)\right.\right. \\
& \left.+i_{b, 0} \sin \left(\theta_{r}-\theta_{s}+\frac{2 \pi}{3}\right)+i_{c, 0} \sin \left(\theta_{r}-\theta_{s}-\frac{2 \pi}{3}\right)\right) \\
& +\Delta i_{B}\left(i_{a, 0} \sin \left(\theta_{r}-\theta_{s}-\frac{2 \pi}{3}\right)+i_{b, 0} \sin \left(\theta_{r}-\theta_{s}\right)\right. \\
& \left.+i_{c, 0} \sin \left(\theta_{r}-\theta_{s}+\frac{2 \pi}{3}\right)\right) \\
& +\Delta i_{C}\left(i_{a, 0} \sin \left(\theta_{r}-\theta_{s}+\frac{2 \pi}{3}\right)\right. \\
& \left.+i_{b, 0} \sin \left(\theta_{r}-\theta_{s}-\frac{2 \pi}{3}\right)+i_{c, 0} \sin \left(\theta_{r}-\theta_{s}\right)\right) \\
& -\Delta i_{a}\left(i_{A, 0} \sin \left(\theta_{s}-\theta_{r}\right)+i_{B, 0} \sin \left(\theta_{s}-\theta_{r}+\frac{2 \pi}{3}\right)\right. \\
& \left.+i_{C, 0} \sin \left(\theta_{s}-\theta_{r}-\frac{2 \pi}{3}\right)\right) \\
& -\Delta i_{b}\left(i_{A, 0} \sin \left(\theta_{s}-\theta_{r}-\frac{2 \pi}{3}\right)+i_{B, 0} \sin \left(\theta_{s}-\theta_{r}\right)\right. \\
& +i_{C, 0} \sin \left(\theta_{s}-\theta_{r}+\frac{2 \pi}{3}\right) \\
& -\Delta i_{c}\left(i_{A, 0} \sin \left(\theta_{s}-\theta_{r}+\frac{2 \pi}{3}\right)\right. \\
& \left.\left.+i_{B, 0} \sin \left(\theta_{s}-\theta_{r}-\frac{2 \pi}{3}\right)+i_{C, 0} \sin \left(\theta_{s}-\theta_{r}\right)\right)\right)
\end{aligned}
$$

